\title{
PENGARUH MEDIA SOSIAL TERHADAP PERILAKU KONSUMTIF ONLINE SHOPPING PADA MAHASISWA FAKULTAS EKONOMI UNIVERSITAS ABDURACHMAN SALEH SITUBONDO
}

\section{THE EFFECTS OF SOCIAL MEDIA ON CONSUMPTIVE ONLINE SHOPPING BEHAVIOR OF THE STUDENTS OF FACULTY OF ECONOMICS AT UNIVERSITY ABDURACHMAN SALEH SITUBONDO}

\author{
Rini Kartika Sari ${ }^{1)}$, Ida Subaida ${ }^{2)}$ \\ ${ }^{1}$ rinikartika1903@gmail.com \\ ${ }^{1,2}$ Fakultas Ekonomi, Universitas Abdurachman Saleh Situbondo
}

\begin{abstract}
ABSTRAK
Kegiatan belanja online merupakan salah satu cara baru untuk berbelanja yang sedang trend digunakan dalam transaksi jual beli. Di kehidupan sehari-hari, penggunaan media sosial di internet sudah semakin berkembang pesat, bukan hanya pada kalangan dewasa saja tetapi juga pada kalangan anak muda (remaja). Adanya Online Shopping dapat memudahkan para remaja berbelanja sesuai keinginan mereka, seperti ingin memiliki barang yang unik atau lebih menarik, barang yang masih jarang digunakan oleh orang banyak dengan edisi terbatas (limited edition), atau juga mengikuti trend masa kini agar kelihatan lebih kekinian. Tujuan dalam penelitian ini pertama, Menjabarkan pengaruh media sosial terhadap perilaku konsumtif pada mahasiswa Fakultas Ekonomi Universitas Abdurachman Saleh Situbondo. Kedua, Mengeksplorasi dampak perkembangan media sosial terhadap perilaku konsumtif pada mahasiswa Fakultas Ekonomi Universitas Abdurachman Saleh Situbondo. Penelitian dilaksanakan menggunakan metode pendekatan deskriptif kualitatif dan deskriptif kuantitatif. Berdasarkan hasil penelitian Uji F (simultan) yang menunjukkan nilai signifikan 0,002 yakni di bawah 5\%. Hal ini berarti bahwa Selective Attention, Motivasi, Kepercayaan, Pendapat dan Pembujukan, serta Kepribadian dan Penyesuaian Diri mempengaruhi mahasiswa untuk berperilaku konsumtif . Pengujian Uji t (parsial), Pendapat dan Pembujukan, serta Kepribadian dan Penyesuaian Diri berpengaruh secara positif dan signifikan terhadap Perilaku Konsumtif pada Mahasiswa Fakultas Ekonomi Universitas Abdurachman Saleh Situbondo.
\end{abstract}

Kata kunci : Media Sosial, Perilaku Konsumtif, Online Shopping

\section{ABSTRACT}

Online shopping is a new way to shop that is being used in buying and selling trends. In everyday life, the use of social media on the internet has been growing rapidly, not only in adults but also among young people (teenagers). The existence of Online Shopping can make it easier for teenagers to shop according to their wishes, such as wanting to have unique or more interesting items, items that are still rarely used by many people with a limited edition, or also to follow 
current trends to look more present. The purpose of this study first, Describe the influence of social media on consumer behavior in the Faculty of Economics, Abdurachman Saleh Situbondo University students. Second, exploring the impact of the development of social media on consumer behavior in the Faculty of Economics, Abdurachman Saleh Situbondo University students. The study was conducted using qualitative descriptive and quantitative descriptive approaches. Based on the results of the $F$ Test (simultaneous) which shows a significant value of 0.002 which is below 5\%. This means that Selective Attention, Motivation, Trust, Opinion and Persuasion, as well as Personality and Self-Adjustment influence students to consumptive behavior. T-test (partial), Opinion and Persuasion, as well as Personality and Adjustment have a positive and significant effect on Consumptive Behavior in Students of the Faculty of Economics, Abdurachman Saleh Situbondo University.

Keywords: Social Media, Consumptive Behavior, Online Shopping

\section{PENDAHULUAN}

Dampak Perkembangan teknologi yang semakin maju, dapat dilihat dari perubahan gaya hidup pada masyarakat. Hal ini juga dapat dilihat dari kecenderungan masyarakat yang selalu aktif menggunakan dunia online. Perkembangan teknologi yang semakin canggih membuat manusia semakin mudah untuk berkomunikasi. Teknologi informasi merupakan suatu teknologi masa kini yang dapat menggabungkan berbagai data, informasi dan sumber untuk dimanfaatkan sebagai ilmu dengan media dan peralatan komunikasi yang modern. Sehingga dengan adanya kemajuan dan perkembangan teknologi khususnya dalam hal telekomunikasi, informasi dan multimedia dapat mempengaruhi perubahan hubungan sosial suatu masyarakat.

Adanya media sosial tidak disia-siakan oleh beberapa pengguna (masyarakat), tak kecuali bagi pengguna lahan bisnis. Lahan bisnis yang dimaksud adalah suatu cara seseorang untuk mempromosikan atau menjual produk, yang biasanya sering disebut dengan online shop. Adanya Trend online shop karena peluang pasar di era digital dan perkembangan teknologi yang semakin canggih. Salah satu yang paling mencolok dari perkembangan teknologi adalah penggunaan gadget dan kecenderungan beraktivitas di dunia maya seperti berbelanja secara online atau lebih sering disebut dengan belanja online (Setiowati dan Jasly, 2012). 
Kota Situbondo memiliki kepadatan penduduk dengan daya beli yang cukup tinggi. Mayoritas masyarakat Situbondo merupakan masyarakat modern termasuk para remajanya, yang saat ini telah menggunakan media online untuk memenuhi kebutuhannya. Hal ini disebabkan karena remaja Situbondo lebih tertarik toko online daripada toko offline, sebab toko offline di Situbondo keragaman produknya terbatas, tidak adanya keberadaan pusat perbelanjaan yang besar dan lengkap seperti Mall di kota-kota besar. Sehingga Online shop menjadi alternatif utama dalam memilih produk yang diinginkan bagi para remaja.

Perilaku konsumtif merupakan tindakan seseorang membeli suatu barang tanpa adanya pertimbangan yang masuk akal dimana seseorang tersebut dalam membeli sesuatu barang tidak didasarkan pada faktor kebutuhan (Sumartono, 2002: 67). Perilaku konsumtif bukan lagi untuk memenuhi kebutuhan semata tetapi untuk memenuhi keinginan yang sifatnya untuk menaikkan prestige, menjaga gengsi ataupun, mengikuti mode. Menurut Soegito (1996), jika dibandingkan dengan bangsa-bangsa di Asia Tenggara, perilaku konsumtif masyarakat Indonesia tergolong berlebihan. Keadaan ini dapat dilihat dari rendahnya tingkat menabung masyarakat Indonesia dibandingkan negara lain seperti Malaysia, Philipina dan Singapura. Hal ini membuktikan bahwa masyarakat Indonesia lebih senang menggunakan uang untuk memenuhi kebutuhan yang tidak penting dengan berperilaku secara konsumtif dalam dunia konsumerisme untuk kelangsungan status dan gaya hidup.

\section{METODE PENELITIAN}

Jenis data yang dianalisis dalam penelitian ini data primer dan data sekunder. Data primer dalam penelitian ini diperoleh melalui penyebaran daftar pernyataan (kuesioner) berkaitan dengan variabel yang diteliti, yang diberikan kepada para mahasiswa Fakultas Ekonomi di Universitas Abdurachman Saleh Situbondo. Jenis data yang ada kaitannya dengan masalah yang diteliti. Data ini dapat diperoleh melalui literatur-literatur, jurnal-jurnal penelitian, majalah maupun data dokumen yang sekiranya diperlukan untuk menyusun penelitian ini. 
Populasi dalam penelitian ini adalah mahasiswa Fakultas Ekonomi Universitas Abdurachman Saleh Situbondo yang pernah membeli produk online shopping menggunakan media sosial. Teknik pengambilan sampel dengan menggunakan teknik purposive sampling yaitu dimana peneliti menggunakan pertimbangan sendiri secara sengaja dalam memilih anggota populasi yang dianggap sesuai dalam memberikan informasi yang diperlukan atau unit sampel yang sesuai dengan kriteria tertentu yang diinginkan oleh peneliti. Jumlah sampel dalam penelitian ini adalah 80 responden.

Analisis data yang digunakan untuk menjawab rumusan masalah dalam penelitian ini adalah metode kuantitatif yaitu dilakukan dengan regresi linier berganda dengan alat bantu software program SPSS.

\section{HASIL PENELITIAN DAN PEMBAHASAN}

\section{Hasil Analisis Data}

\section{Pengujian Validitas}

Menurut Sugiono (2004: 267), validitas adalah suatu ukuran yang menunjukkan tingkat kevalidan atau kesahihan suatu instrumen. Item kuesioner dinyatakan valid apabila nilai $r_{\text {hitung }}>r_{\text {tabel }}(n-2)$. Pengujian validitas selengkapnya dapat dilihat pada tabel 1 berikut ini:

Tabel 1. Hasil Uji Validitas

\begin{tabular}{|l|c|c|c|}
\hline \multicolumn{1}{|c|}{ Butir Pertanyaan } & $\mathbf{r}_{\text {hitung }}$ & $\mathbf{r}_{\text {tabel }}$ & Keterangan \\
\hline Selective Attention $\left(\mathbf{X}_{\mathbf{1}}\right)$ & 0,857 & 0,2199 & Valid \\
\hline X1_1 & 0,844 & 0,2199 & Valid \\
\hline X1_2 & 0,866 & 0,2199 & Valid \\
\hline X1_3 & 0,837 & 0,2199 & Valid \\
\hline Motivasi $\left(\mathbf{X}_{\mathbf{2}}\right)$ & 0,753 & 0,2199 & Valid \\
\hline X2_1 & 0,739 & 0,2199 & Valid \\
\hline X2_2 & 0,661 & 0,2199 & Valid \\
\hline X2_3 & 0,837 & 0,2199 & Valid \\
\hline X2_4 & 0,837 & 0,2199 & Valid \\
\hline Kepercayaan $\left(\mathbf{X}_{\mathbf{3}}\right)$ & & \\
\hline X3_1 & 0,832 & 0,2199 & Valid \\
\hline X3_2 & 0,832 & 0,2199 & Valid \\
\hline Pendapat dan Pembujukan $\left(\mathbf{X}_{4}\right)$ & \\
\hline X4_1 &
\end{tabular}




\begin{tabular}{|l|l|l|l|}
\hline X5_1 & 0,872 & 0,2199 & Valid \\
\hline X5_2 & 0,872 & 0,2199 & Valid \\
\hline Perilaku Konsumtif (Y) & 0,840 & 0,2199 & Valid \\
\hline Y_1 & 0,858 & 0,2199 & Valid \\
\hline Y_2 & 0,838 & 0,2199 & Valid \\
\hline Y_3
\end{tabular}

Berdasarkan dari tabel diatas dapat diketahui bahwa semua indikator valid untuk variabel bebas dan terikat karena nilai $r_{\text {hitung }}$ lebih besar dari $r_{\text {tabel }}$.

\section{Pengujian Reliabilitas}

Reliabilitas adalah alat yang digunakan untuk mengetahui tingkat keandalan dari alat ukur yang dipakai. Reliabilitas dilakukan dengan menggunakan metode Cronbach Alpha, dimana kuisioner dikatakan reliabel jika nilai Cronbach Alpha lebih besar dari 0,70. Hasil pengujian reliabilitas untuk masing-masing variabel yang diringkas pada tabel 2 berikut ini:

Tabel 2. Hasil Uji Reliabilitas

\begin{tabular}{|l|c|c|c|}
\hline \multicolumn{1}{|c|}{ Kategori } & Nilai & Nilai Cut Off & Keterangan \\
\hline Selective Attention $\left(\mathrm{X}_{1}\right)$ & 0,919 & 0,70 & Reliabel \\
\hline Motivasi $\left(\mathrm{X}_{2}\right)$ & 0,863 & 0,70 & Reliabel \\
\hline Kepercayaan $\left(\mathrm{X}_{3}\right)$ & 0,873 & 0,70 & Reliabel \\
\hline Pendapat dan Pembujukan $\left(\mathrm{X}_{4}\right)$ & 0,870 & 0,70 & Reliabel \\
\hline Kepribadian dan Penyesuaian Diri $\left(\mathrm{X}_{5}\right)$ & 0,897 & 0,70 & Reliabel \\
\hline Perilaku Konsumtif $(\mathrm{Y})$ & 0,899 & 0,70 & Reliabel \\
\hline
\end{tabular}

Uji reliabilitas ini memberikan indikasi bahwa kehandalan kuisioner yang digunakan sebagai alat pengukur untuk tiap variabel termasuk pada kategori berkorelasi tinggi dan diterima, karena setiap nilai alpha melebihi nilai Alpha Cronbach yaitu 0,70 maka semua variabel adalah reliabel.

\section{Analisis Persamaan Regresi Linear Berganda}

Menurut Supranto (2000: 204) analisis ini digunakan untuk mengetahui pengaruh antara variabel Selective Attention $\left(\mathrm{X}_{1}\right)$, Motivasi $\left(\mathrm{X}_{2}\right)$, Kepercayaan $\left(\mathrm{X}_{3}\right)$, Pendapat dan Pembujukan $\left(\mathrm{X}_{4}\right)$, Kepribadian dan Kesesuaian Diri $\left(\mathrm{X}_{5}\right)$ terhadap Perilaku Konsumtif (Y), dengan rumus: 


$$
\mathrm{Y}=\mathrm{b}_{0}+\mathrm{b}_{1} \mathrm{X}_{1}+\mathrm{b}_{2} \mathrm{X}_{2}+\mathrm{b}_{3} \mathrm{X}_{3}+\mathrm{b}_{4} \mathrm{X}_{4}+\mathrm{b}_{5} \mathrm{X}_{5}+e
$$

Dimana:

$$
\begin{aligned}
& \mathrm{Y}=\text { Perilaku Konsumtif } \\
& \mathrm{b}_{0}=\text { Bilangan konstanta } \\
& \mathrm{X}_{1}=\text { Selective Attention } \\
& \mathrm{X}_{2}=\text { Motivasi } \\
& \mathrm{X}_{3}=\text { Kepercayaan } \\
& \mathrm{X}_{4}=\text { Pendapat dan Pembujukan } \\
& \mathrm{X}_{5}=\quad \text { Kepribadian dan Kesesuaian Diri } \\
& \mathrm{b}_{1} \mathrm{~b}_{2} \mathrm{~b}_{3} \mathrm{~b}_{4} \mathrm{~b}_{5}=\text { koefisien Regresi } \\
& e \quad=\text { Error }
\end{aligned}
$$

Berdasarkan estimasi regresi berganda dengan program SPSS 21 diperoleh hasil seperti tabel 3 berikut ini :

Tabel 3. Hasil Analisa Regresi Linier Berganda

\begin{tabular}{|l|r|r|r|r|}
\cline { 2 - 4 } & \multicolumn{2}{|c|}{$\begin{array}{c}\text { Unstandardized } \\
\text { Coefficients }\end{array}$} & \multicolumn{2}{c|}{$\begin{array}{c}\text { Standardized } \\
\text { Coefficients }\end{array}$} \\
\cline { 2 - 4 } Model & \multicolumn{1}{|c|}{ B } & Std. Error & \multicolumn{2}{c|}{ Beta } \\
\hline (Constant) & $-1,528 \mathrm{E}-16$ &, 102 &, 000 \\
Selective Attention &,- 009 &, 104 &,- 009 &,- 082 \\
\hline Motivasi &, 056 &, 105 &, 056 &, 539 \\
Kepercayaan &,- 173 &, 108 &,- 173 & $-1,598$ \\
Pendapat dan Pembujukan &, 362 &, 108 &, 362 & 3,359 \\
Kepribadian dan Penyesuain &, 297 &, 107 &, 297 & 2,773 \\
Diri & &, 297 & \\
\hline
\end{tabular}

Hasil perhitungan regresi tersebut selanjutnya digunakan untuk menyusun persamaan regresi sebagai berikut :

$$
\begin{aligned}
& Y=a+b_{1} X_{1}+b_{2} X_{2}+b_{3} X_{3}+b_{4} X_{4}+b_{5} X_{5}+e \\
& Y=-1,528 E-16-0,009 X_{1}+0,056 X_{2}-0,173 X_{3}+0,362 X_{4}+0,297 X_{5}+e
\end{aligned}
$$

Keterangan :

$\mathrm{Y}=$ Variabel terikat yang nilainya akan diprediksi atau diramalkan oleh variabel bebas. Penelitian ini yang menjadi variabel terikat adalah Perilaku Konsumtif. 


\section{Volume 3 , Nomor 1 ,}

a = Merupakan konstanta (a) yang menunjukkan bahwa apabila tanpa dipengaruhi oleh variabel (X) faktor-faktor perilaku konsumtif maka prediksi nilai perilaku konsumtif sebesar 1,528 E -16

$-0,009 \mathrm{X}_{1}=-0,009$ merupakan koefisien regresi dari variabel Selective Attention $\left(\mathrm{X}_{1}\right)$ terhadap Perilaku Konsumtif $(\mathrm{Y})$ adalah negatif. Artinya bahwa apabila Selective Attention naik 1 satuan maka Perilaku Konsumtif akan menurun sebesar $0,9 \%$ dengan asumsi variabel bebas lainnya relatif konstan.

$0,056 \mathrm{X}_{2}=0,056$ merupakan koefisien regresi dari variabel Motivasi $\left(\mathrm{X}_{2}\right)$ terhadap Perilaku Konsumtif (Y) adalah positif. Artinya bahwa apabila Motivasi meningkat 1 satuan maka Perilaku Konsumtif akan meningkat sebesar $5,6 \%$ dengan asumsi variabel bebas lainnya relatif konstan.

$-0,173 \mathrm{X}_{3}=-0,173$ merupakan koefisien regresi dari variabel Kepercayaan $\left(\mathrm{X}_{3}\right)$ terhadap Perilaku Konsumtif (Y) adalah negatif. Artinya bahwa apabila Kepercayaan naik 1 satuan maka Perilaku Konsumtif akan menurun sebesar 17,3\% dengan asumsi variabel bebas lainnya relatif konstan.

0,362 $\mathrm{X}_{4}=0,362$ merupakan koefisien regresi dari variabel Pendapat dan Pembujukan $\left(\mathrm{X}_{4}\right)$ terhadap Perilaku Konsumtif $(\mathrm{Y})$ adalah positif. Artinya bahwa apabila Pendapat dan Pembujukan meningkat 1 satuan maka Perilaku Konsumtif akan menurun sebesar 36,2\% dengan asumsi variabel bebas lainnya relatif konstan.

0,297 $\mathrm{X}_{5}=0,297$ merupakan koefisien regresi dari variabel Kepribadian dan Penyesuain Diri $\left(\mathrm{X}_{5}\right)$ terhadap Perilaku Konsumtif $(\mathrm{Y})$ adalah positif. Artinya bahwa apabila Kepribadian dan Penyesuain Diri meningkat 1 satuan maka Perilaku Konsumtif akan meningkat sebesar 29,7\% dengan asumsi variabel bebas lainnya relatif konstan.

\section{Uji F (Pengujian hipotesis secara simultan)}

Uji F digunakan untuk mengetahui tingkat signifikan variabel bebas (independent) secara simultan terhadap variabel terikat (dependent). Pengujian 
didasarkan pada perbandingan angka $\mathrm{F}_{\text {hitung }}$ dengan $\mathrm{F}_{\text {tabel }}$ pada taraf signifikan 5\%, sebagai berikut :

Tabel 4. Hasil Uji F (Simultan)

\begin{tabular}{|c|c|c|c|c|c|}
\hline Model & Sum of Squares & $\mathrm{df}$ & Mean Square & $\mathrm{F}$ & Sig. \\
\hline 1 Regression & 17,500 & 5 & 3,500 & 4,211 &, $002^{b}$ \\
\hline Residual & 61,500 & 74 &, 831 & & \\
\hline Total & 79,000 & 79 & & & \\
\hline
\end{tabular}

Hasil analisis diperoleh nilai $\mathrm{F}_{\text {hitung }}$ sebesar 4,211 dan untuk nilai $\mathrm{F}_{\text {tabel }}$ sebesar 2,34. Dengan menggunakan batas signifikansi 0,05, maka diperoleh nilai signifikansi tersebut lebih kecil dari 0,05. Hal ini menunjukkan bahwa secara serempak variabel Selective Attention, Motivasi, Kepercayaan, Pendapat dan Pembujukan, serta Kepribadian dan Penyesuaian Diri berpengaruh secara nyata dan signifikan terhadap Perilaku Konsumtif.

\section{Uji t ( Uji Hipotesis Secara Parsial )}

Untuk mengetahui pengaruh masing-masing koefisien regresi variabel independent terhadap variabel dependent maka digunakan uji t. Pengujian ini dilakukan dengan membandingkan nilai $t_{\text {hitung }}$ dengan nilai $\mathrm{t}_{\text {tabel }}$. Hasil uji $\mathrm{t}$ tersebut sebagai berikut :

Tabel 5. Hasil Uji t

\begin{tabular}{|l|r|r|c|}
\hline \multicolumn{1}{|c|}{ Faktor Independent } & \multicolumn{1}{c|}{$\mathbf{t}_{\text {hitung }}$} & $\mathbf{t}_{\text {tabel }}$ & \multicolumn{1}{c|}{ Sig. } \\
\hline Selective Attention $\left(\mathrm{X}_{1}\right)$ &,- 082 & 1,99254 & 0,935 \\
\hline Motivasi $\left(\mathrm{X}_{2}\right)$ &, 539 & 1,99254 & 0,592 \\
\hline Kepercayaan $\left(\mathrm{X}_{3}\right)$ & $-1,598$ & 1,99254 & 0,114 \\
\hline Pendapat dan Pembujukan $\left(\mathrm{X}_{4}\right)$ & 3,359 & 1,99254 & 0,001 \\
\hline Kepribadian dan Penyesuaian Diri $\left(\mathrm{X}_{5}\right)$ & 2,773 & 1,99254 & 0,007 \\
\hline
\end{tabular}

Pengaruh masing-masing faktor independent (Selective Attention, Motivasi, Kepercayaan, Pendapat dan Pembujukan serta Kepribadian dan Penyesuaian Diri) terhadap faktor dependent (Perilaku Konsumtif) dapat dijelaskan sebagai berikut :

1) Pengaruh Selective Attention $\left(\mathrm{X}_{1}\right)$ terhadap Perilaku Konsumtif. Hasil uji $\mathrm{t}$ diperoleh $\mathrm{t}_{\text {hitung }}$ sebesar $-0,082>\mathrm{t}_{\text {tabel }} 1,99254$ dan taraf signifikasinya 0,935 
$>$ 0,05 sehingga Selective Attention tidak berpengaruh terhadap Perilaku Konsumtif.

2) Pengaruh Motivasi $\left(\mathrm{X}_{2}\right)$ terhadap Perilaku Konsumtif. Hasil uji t diperoleh $\mathrm{t}_{\text {hitung }}$ sebesar $0,539<\mathrm{t}_{\text {tabel }} 1,99254$ dan taraf signifikasinya $0,592>0,05$ sehingga Motivasi tidak berpengaruh terhadap Perilaku Konsumtif.

3) Pengaruh Kepercayaan $\left(X_{3}\right)$ terhadap Perilaku Konsumtif. Hasil uji t diperoleh $t_{\text {hitung }}$ sebesar $-1,598>t_{\text {tabel }}-1,99254$ dan taraf signifikasinya $0,114>0,05$ sehingga Kepercayaan tidak berpengaruh terhadap Perilaku Konsumtif.

4) Pengaruh Pendapat dan Pembujukan $\left(X_{4}\right)$ terhadap Perilaku Konsumtif. Hasil uji $\mathrm{t}$ diperoleh $\mathrm{t}_{\text {hitung }}$ sebesar 3,359 $>\mathrm{t}_{\text {tabel }}$ 1,99254 dan taraf signifikasinya $0,001<0,05$ sehingga Pendapat dan Pembujukan berpengaruh terhadap Perilaku Konsumtif.

5) Pengaruh Kepribadian dan Penyesuaian Diri $\left(\mathrm{X}_{5}\right)$ terhadap Perilaku Konsumtif. Hasil uji t diperoleh $t_{\text {hitung }}$ sebesar 2,773 $>t_{\text {tabel }} 1,99254$ dan taraf signifikasinya $0,007<0,05$ sehingga Pendapat dan Pembujukan berpengaruh terhadap Perilaku Konsumtif.

\section{Uji Asumsi Klasik}

\section{a. Uji Normalitas}

Distribusi normal akan membentuk satu garis lurus diagonal dan ploting data residual akan dibandingkan dengan garis diagonal (Ghozali, 2011:160). Hasil perhitungan uji normalitas dengan melihat dari segi grafik yang ditunjukan pada gambar grafik p-p plot berikut ini: 


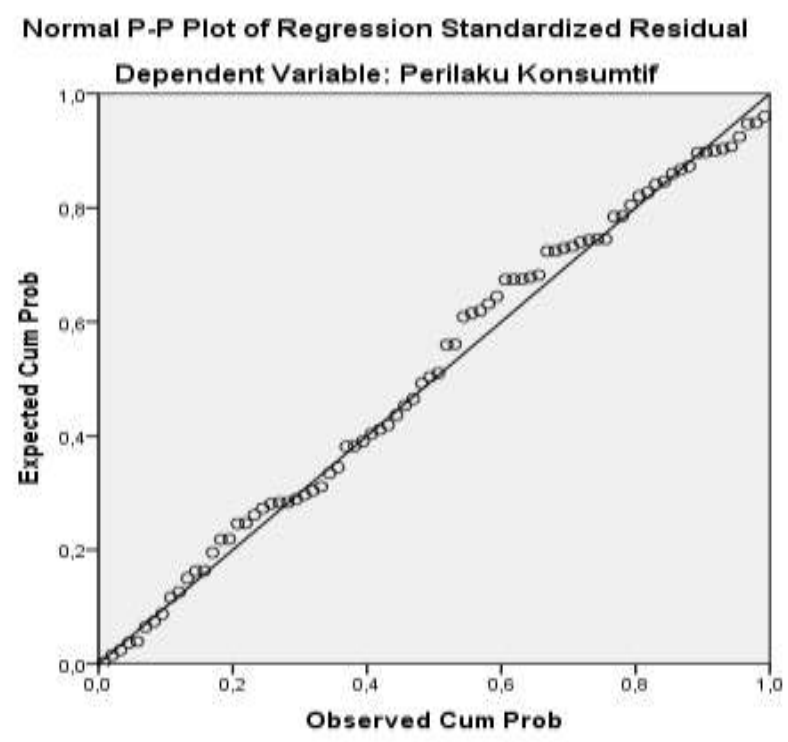

Gambar 1. Hasil Uji Normalitas Secara Grafik

Berdasarkan gambar diatas grafik normal plot terlihat titik-titik menyebar di sekitar garis diagonal, serta penyebarannya mengikuti arah garis diagonal. Grafik ini menunjukkan bahwa model regresi layak dipakai karena asumsi normalitas.

\section{b. Uji Multikolinieritas}

Pengujian multikolinieritas dilakukan untuk menguji apakah pada model regresi ditemukan adanya kolerasi antara variabel independen (Selective Attention, Motivasi, Kepercayaan, Pendapat dan Pembujukan, serta Kepribadian dan Penyesuaian Diri), untuk mendeteksi adanya masalah multikolinieritas maka dapat dilakukan dengan melihat nilai tolerance dan variance inflation factor (VIF) serta besaran kolerasi variabel independen.

Tabel 4. Hasil Uji Multikolinieritas

\begin{tabular}{|c|c|c|c|}
\hline \multirow[b]{2}{*}{ Model } & \multirow[b]{2}{*}{ Sig. } & \multicolumn{2}{|c|}{ Collinearity Statistics } \\
\hline & & Tolerance & VIF \\
\hline 1 (Constant) & 1,000 & & \\
\hline Selective Attention & ,935 & 965 & 1,036 \\
\hline Motivasi & ,592 & ,959 & 1,042 \\
\hline Kepercayaan &, 114 & 895 & 1,118 \\
\hline Pendapat dan Pembujukan &, 001 & ,905 & 1,104 \\
\hline Kepribadian dan Penyesuain Diri & 007 & 919 & 1,088 \\
\hline
\end{tabular}

Data diatas menunjukan bahwa variabel Selective Attention memiliki nilai Tolerance 0,965 > 0,10 dan nilai VIF 1,036 < 10, variabel Motivasi memiliki nilai 


\section{Volume 3 , Nomor 1 ,}

Tolerance 0,959 > 0,10 dan nilai VIF 1,042 < 10, variabel Kepercayaan memiliki nilai Tolerance 0,895 $>0,10$ dan nilai VIF $1,118<10$, variabel Pendapat dan Pembujukan memiliki nilai Tolerance $0,905>0,10$ dan nilai VIF 1,104 < 10 serta variabel Kepribadian dan Penyesuaian Diri memiliki nilai Tolerance 0,919>0,10 dan nilai VIF $1,088<10$. Dari penjelasan tersebut membuktikan bahwa tidak terjadi multikolinieritas pada masing-masing variabel.

\section{c. Uji Heteroskedatisitas}

Heteroskedastisitas menunjukan bahwa variasi variabel tidak sama untuk semua pengamatan. Pada heteroskedastisitas kesalahan tidak terjadi secara acak tetapi menunjukan hubungan yang sistematis sesuai dengan besarnya satu atau lebih variabel. Berdasarkan hasil pengolahan data, maka hasil Scatterplot dapat dilihat pada gambar berikut :

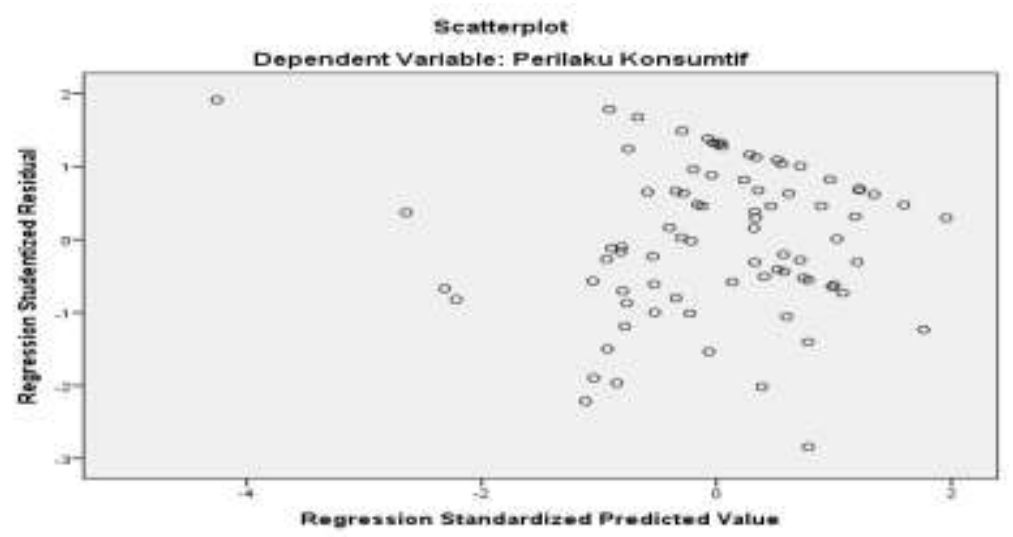

\section{Pembahasan}

Gambar 2. Hasil Uji Heteroskedastisidas

a. Pengaruh Selective Attention Terhadap Perilaku Konsumtif

Hipotesis pertama, menyatakan bahwa Selective Attention memiliki pengaruh terhadap Perilaku Konsumtif. Hasil analisis regresi menunjukkan nilai variabel Selective Attention sebesar -0,009, sedangkan nilai signifikansi sebesar 0,935 > 0,05. Hal ini mengidentifikasikan bahwa variabel Selective Attention tidak memiliki pengaruh yang signifikan terhadap Perilaku Konsumtif.

b. Pengaruh Motivasi Terhadap Perilaku Konsumtif 
Hipotesis kedua, menyatakan bahwa Motivasi memiliki pengaruh terhadap Perilaku Konsumtif. Hasil analisis regresi menunjukkan nilai variabel Motivasi sebesar 0,056, sedangkan nilai signifikansi sebesar 0,592 >0,05. Hal ini mengidentifikasikan bahwa variabel Motivasi tidak memiliki pengaruh yang signifikan terhadap Perilaku Konsumtif.

c. Pengaruh Kepercayaan Terhadap Perilaku Konsumtif

Hipotesis ketiga, menyatakan bahwa Kepercayaan memiliki pengaruh terhadap Perilaku Konsumtif. Hasil analisis regresi menunjukkan nilai variabel Kepercayaan sebesar -0,173, sedangkan nilai signifikansi sebesar 0,114 >0,05. Hal ini mengidentifikasikan bahwa variabel Kepercayaan tidak memiliki pengaruh terhadap Perilaku Konsumtif.

d. Pengaruh Pendapat dan Pembujukan Terhadap Perilaku Konsumtif

Hipotesis keempat, menyatakan bahwa Pendapat dan Pembujukan memiliki pengaruh terhadap Perilaku Konsumtif. Hasil analisis regresi menunjukkan nilai variabel Pendapat dan Pembujukan sebesar 0,362, sedangkan nilai signifikansi sebesar 0,001 $<0,05$. Hal ini mengidentifikasikan bahwa variabel Pendapat dan Pembujukan memiliki pengaruh yang signifikan terhadap Perilaku Konsumtif.

e. Pengaruh Kepribadian dan Penyesuaian Diri Terhadap Perilaku Konsumtif

Hipotesis kelima, menyatakan bahwa Kepribadian dan Penyesuaian Diri memiliki pengaruh terhadap Perilaku Konsumtif. Hasil analisis regresi menunjukkan nilai variabel Kepribadian dan Penyesuaian Diri sebesar 0,297, sedangkan nilai signifikansi sebesar 0,007 $<0,05$. Hal ini mengidentifikasikan bahwa variabel Kepribadian dan Penyesuaian Diri memiliki pengaruh yang signifikan terhadap Perilaku Konsumtif. 


\section{PENUTUP}

\section{Kesimpulan}

Berdasarkan hasil penelitian yang telah diuraikan, maka dapat ditarik kesimpulan, yaitu :

a. Online shop pada media sosial berpengaruh positif dan signifikan terhadap Perilaku Konsumtif pada Mahasiswa Fakultas Ekonomi Universitas Abdurachman Saleh Situbondo. Hal ini ditunjukkan bahwa Selective Attention, Motivasi, Kepercayaan, Pendapat dan Pembujukan, serta Kepribadian dan Penyesuaian Diri mempengaruhi mahasiswa untuk berperilaku konsumtif diperkuat dengan adanya uji $\mathrm{F}$ (simultan) yang menunjukkan nilai signifikan 0,002 yakni di bawah $5 \%$.

b. Pengujian Uji t (parsial), Pendapat dan Pembujukan, serta Kepribadian dan Penyesuaian Diri berpengaruh secara positif dan signifikan terhadap Perilaku Konsumtif pada Mahasiswa Fakultas Ekonomi Universitas Abdurachman Saleh Situbondo.

\section{Saran}

a. Dengan adanya kemajuan teknologi di bidang IT, dimana semua transaksi pembayaran sudah berbasis IT maka perlu dievaluasi kembali apakah harga dan kualitas produk masih diperlukan atau perlu dimodifikasi. Karena kecenderungan sekarang pelanggan lebih membandingkan harga dan kualitas produk dari berbagai toko online shop yang pernah dibelinya.

b. Bagi penjual online shop melalui media sosial, penjual dalam melakukan kinerja memasarkan produk melalui online yang lebih kreatif agar dapat meningkatkan laba, serta mempengaruhi perilaku konsumtif banyak konsumen yang membeli produk online tersebut. 


\section{DAFTAR PUSTAKA}

Andreas, Kaplan M., Haenlein Michael. 2010. "Users of the world, unite! The challenges and opportunities of social media". Business Horizons 53 (1). p. 61.

Ferdinand, Augusty. 2014. Structural Equation Modeling dalam Penelitian Manajemen. Semarang: Universitas Dipenogoro.

Hidayat, Taufik, 2008. Panduan Membuat Toko Online dengan OS Commerce. Mediakita: Jakarta.

Jony, Wong. 2010. Internet Marketing for Beginners. Jakarta: Elex Media Komputindo.

Setiowati, A, K, W., dan By, Jasly. 2012. Sikap Online Shopping Dan Niat Pencarian Informasi Terhadap Niat dan Perilaku Belanja. Jurnal Manajemen Bisnis. Vol. 2. (1): 3-8.

Sugiono. 2004. Statistik Untuk Penelitian. Bandung : CV.Alfabeta.

Sugiyono. 2009. Metode Penelitian Administrasi. Bandung: Alfabeta.

Sumartono. 2002. Terperangkap dalam Iklan : Meneropong Imbas Pesan Iklan Televisi. Bandung : Penerbit Alfabeta.

Supranto, J. 2001. Statistik : Teori dan Aplikasi. Edisi 5, Jilid II. Jakarta : Erlangga.

Tadashi, Fukutake. 1998. Masyarakat Jepang Dewasa Ini. Jakarta : PT Gramedia Pustaka 